\title{
Assessment of the Serotonin and Norepinephrine Reuptake Blocking Properties of Duloxetine in Healthy Subjects
}

Julie E. Turcotte, M.D., Guy Debonnel, M.D., Claude de Montigny, M.D., Ph.D., Chantal Hébert, R.N., and Pierre Blier, M.D., Ph.D.

Duloxetine is a dual inhibitor of norepinephrine (NE) and serotonin (5-HT) uptake. Initial trials conducted in depressed patients using regimens of $20 \mathrm{mg} /$ day or less did not convincingly demonstrate its efficacy as an antidepressant. The aim of this study was to assess the effects of duloxetine on the 5-HT and NE reuptake processes in healthy human volunteers. Twenty-seven healthy young males without a history of psychiatric disorder were randomly assigned to four groups, each group receiving one of the following daily drug regimens: placebo, clomipramine (a potent 5-HT/NE reuptake blocker) $100 \mathrm{mg} /$ day,

duloxetine $20 \mathrm{mg} /$ day, or duloxetine $60 \mathrm{mg} /$ day. In order to assess the NE reuptake process, the pressor response to intravenous tyramine (4 and $6 \mathrm{mg}$ ) was measured.

Determination of the whole blood 5-HT content was used to evaluate the 5-HT reuptake blockade. These measurements were performed at baseline and repeated after 7 and 14 days of drug intake. Both duloxetine, at doses of 20 to $60 \mathrm{mg} /$ day, and clomipramine significantly interfered with the 5-HT reuptake process, as demonstrated by marked decreases in blood 5-HT concentrations. However, the same doses of duloxetine, unlike clomipramine, failed to impede the usual increase in blood pressure that follows a tyramine intravenous infusion, indicating that clomipramine but not duloxetine blocked NE reuptake. At doses tested in a population of healthy volunteers, duloxetine acted as a selective 5-HT reuptake inhibitor, having no clear effect on the NE reuptake process. Nevertheless, given that the highest dose of duloxetine increased supine systolic blood pressure, it is possible that it represents the threshold regimen for NE reuptake inhibition.

[Neuropsychopharmacology 24:511-521, 2001] (C) 2001 American College of Neuropsychopharmacology. Published by Elsevier Science Inc.
KEY WORDS: Antidepressants; Reuptake inhibition; Clomipramine; Duloxetine; Tyramine; Platelets

Most antidepressants used today increase the efficacy of the serotoninergic (5-HT) and/or noradrenergic (NE) neurotransmission. Thus, modulation of the synaptic availability of these two neurotransmitters is thought to

From the Neurobiological Psychiatry Unit, Faculty of Medicine, McGill University, Montreal, Canada.

Address correspondence to: Pierre Blier, M.D., Ph.D., Department of Psychiatry, Brain Institute, PO Box 100256, University of Florida, Gainesville, FL 32610.

Received April 27, 2000; revised October 6, 2000; accepted October 18,2000 be involved in the therapeutic effects of these drugs (Blier and de Montigny 1999; Delgado et al. 1999). Blockade of the reuptake of 5-HT and/or NE by tricyclic antidepressants (TCAs), or of 5-HT only by selective 5-HT reuptake inhibitors (SSRIs) leads to a marked improvement of depressive symptoms in about $70 \%$ of patients. About $30 \%$ of them remain unsatisfactorily improved despite adequate dosing, however. Treatments combining NE and 5-HT reuptake blockade have been reported to produce more robust antidepressant effects in selected groups of depressed patients (Nelson et al. 1991; Seth et al. 1992; Nelson 1998; Poirier and Boyer 1999). Development of molecules acting as dual inhibitors of 5-HT and NE reuptake might thus lead to 
faster-acting and more efficacious antidepressant treatments.

Duloxetine [LY248686; (+)-N-methyl-3-(1-naphthalenyloxy)-2 thiophenepropanamine], a compound now being investigated as an antidepressant, is endowed with the property of blocking both the 5-HT and NE reuptake processes (Wong et al. 1993; Engleman et al. 1995; Kasamo et al. 1996; Fuller et al. 1994; Kihara and Ikeda 1995; Wong 1998), while being devoid of significant affinities for other neuronal receptors (Wong et al. 1993). Animal studies have shown that, in vitro and ex vivo, duloxetine inhibits $\left[{ }^{3} \mathrm{H}\right] 5-\mathrm{HT}$ and $\left[{ }^{3} \mathrm{H}\right] \mathrm{NE}$ in hypothalamic and cortical synaptosomes (Wong et al. 1993; Engleman et al. 1995), as well as in hippocampus slices (Kasamo et al. 1996). Radioligand-binding studies support this finding in that duloxetine antagonizes the binding of $\left[{ }^{3} \mathrm{H}\right]$ paroxetine and $\left[{ }^{3} \mathrm{H}\right]$ tomoxetine to the 5-HT and NE carriers, respectively (Wong et al. 1993; Engleman et al. 1995). Duloxetine prevents the p-chloroamphetamine-induced depletion of 5-HT in the rat brain (Wong et al. 1993; Engleman et al. 1995; Kasamo et al. 1996; Fuller et al. 1994), and also antagonizes the depletion of $\mathrm{NE}$ induced by 6-hydroxydopamine in mice hearts and in the hypothalamus of rats (Fuller et al. 1994). Microdialysis studies indicate that acute systemic duloxetine administration induces a large increase in extracellular levels of 5-HT and NE in the hypothalamus and cortex of rats (Engleman et al. 1995; Kihara and Ikeda 1995). Finally, using an electrophysiological approach, Kasamo et al. (1996) found that, when given acutely, duloxetine suppresses the spontaneous firing of both the dorsal raphe 5-HT and the locus coeruleus NE neurons, indicating an increased availability of these neurotransmitters in the immediate vicinity of their somatodendritic receptors regulating their firing activity.

In spite of the pharmacology of duloxetine compared to that of currently marketed antidepressants and of promising results in depressed subjects (Berk et al. 1997), controlled trials conducted in depressed patients have yet to convincingly demonstrate its efficacy as an antidepressant. In the largest controlled study reported to date for patients with major depression, duloxetine was administered at daily doses of 5, 10, and $20 \mathrm{mg}$, and was compared to placebo and to $150 \mathrm{mg} /$ day of clomipramine (Joubert et al. 1997). A preliminary indication in that study is that duloxetine was not as effective as clomipramine. In contrast, venlafaxine (Effexor() has been shown to block reuptake of both 5-HT and NE and to be an effective antidepressant (Yardley et al. 1990; Derivan et al. 1995; Nierenberg et al. 1994). It is possible that, in doses tested thus far, duloxetine has not adequately blocked both 5-HT and NE reuptake processes and as a result has not been found as efficacious as expected.

The main goal of this study was to examine the ef- fects of duloxetine on the 5-HT and NE reuptake processes in healthy volunteers. The secondary objective was to compare the potency of different doses of duloxetine in blocking $\mathrm{NE}$ and 5-HT reuptake processes to that of placebo and the reference drug, clomipramine.

\section{SUBJECTS AND METHODS}

\section{Study Subjects}

Volunteers were recruited via a newspaper advertisement. Prior to their inclusion in the study, all volunteers underwent a structured clinical interview (SCID for non-patients), a physical examination, and laboratory tests consisting of a complete blood count, electrolytes, liver enzymes, urea and creatinine, urine drug screening, and an electrocardiogram. Participants met the following inclusion criteria: 1) male, between the ages of 18 and 40 years old; 2 ) normal body weight (body mass index not in the obese range); 3) no significant medical illness, including migraines, high blood pressure $(\mathrm{BP}>$ 140/90), hepatitis B or HIV; 4) not taking medication on a regular basis; and 5) no evidence suggestive of a past or present history of mental disorders.

Subjects were excluded from the study for any of the following reasons: 1) use of an investigational drug within 30 days of study entry; 2) orthostatic hypotension (fall in systolic BP $>10 \mathrm{~mm} \mathrm{Hg}$ ); 3) use of any psychotropic medication or illicit drugs; 4) regular use of any medication other than acetaminophen or vitamins and mineral supplements; 5) smoking more than 10 cigarettes per day; and 6) history of difficult phlebotomy (e.g., vasovagal reaction). Any significant abnormality upon physical examination or laboratory tests was also a reason for exclusion.

\section{Randomization}

Volunteers were randomly assigned to one of four treatment groups: placebo, clomipramine $100 \mathrm{mg} /$ day, duloxetine $20 \mathrm{mg} /$ day (low-dose), or duloxetine 60 mg/day (high-dose). Thirty subjects qualified for the study, but three dropped out because of adverse events (one in each of the following groups: placebo, clomipramine and duloxetine $60 \mathrm{mg} /$ day). A total of twentyseven subjects completed the protocol, and only these subjects were considered in the analysis.

\section{Drug Regimens and Timing of Assessments}

Each subject was randomly assigned to one of the four treatment arms. If assigned to either placebo or a duloxetine arm, neither the subject nor the investigator could tell whether the subject was given duloxetine or placebo, as the study drug capsules were identical in appearance. If assigned to the clomipramine arm, the sub- 
ject was given clomipramine tablets which were identifiable as such. In all arms, subjects took study drug in divided doses (twice daily) for a total of 14 days. Subjects in the low-dose duloxetine arm started on the full dose and received the same dose for the entire study period. The doses were gradually escalated in the high-dose duloxetine and clomipramine arms in order to minimize unwanted side effects. Subjects in the high-dose duloxetine arm received $20 \mathrm{mg}$ /day for three days, $40 \mathrm{mg} /$ day for four days, and then $60 \mathrm{mg} /$ day for the next seven days. Dose-escalation for the clomipramine group was as follows: $25 \mathrm{mg} /$ day for three days, $50 \mathrm{mg} /$ day for four days, and then $100 \mathrm{mg} /$ day for the last seven days. Plasma levels of the drugs were determined by standard HPLC methods approved by Eli Lilly \& Co (Sharma et al. 2000).

The assessment of NE and 5-HT reuptake processes was performed at baseline (day 0 ), on day 7 and on day 14. As both duloxetine and clomipramine have halflives of less than 24 hours, it was considered that four days at the same dose would be sufficient to achieve near-steady-state plasma levels. To insure maximal biological response during the reuptake assessments, participants were instructed to take their last dose of medication 2 to 3 hours prior to the beginning of testing. The peak plasma level of duloxetine is reached after 2 to 5 hours (Sharma et al. 2000), while that of clomipramine is typically reached after 2 hours.

\section{Assessment of 5-HT Reuptake}

Platelet 5-HT content has become a widely used tool for studying the presynaptic serotoninergic neurons. Blood platelets can take up, store and release 5-HT in a fashion very similar to that of 5-HT neurons, but lack the enzymatic system necessary to synthesize 5-HT and most of the 5-HT receptors subtypes (Pletscher 1968). Thus, any 5-HT present in platelets has been taken up by the transport system, and platelet 5-HT content is considered to provide an indirect indication of 5-HT reuptake activity by 5-HT neurons. Once 5-HT uptake has been effectively blocked and as it remains blocked, the platelet 5-HT content gradually decreases as older platelets which have previously taken up 5-HT are removed from the circulation and are replaced by new ones incapable of taking up 5-HT. Moreover, as a very large proportion $(90-95 \%)$ of blood $5-\mathrm{HT}$ is sequestrated in the platelets, whole blood 5-HT content largely reflects platelet 5-HT content (Demet et al. 1978; Artigas et al. 1985; Zucker 1965).

In this study, whole blood 5-HT was measured by high performance liquid chromatography (HPLC) with electrochemical detection, basically as described by Artigas et al. (1985). Two indices were used to evaluate 5-HT reuptake: 1) depletion of blood 5-HT content, measured on day 7 and day 14, compared to the baseline level; and
2) that same 5-HT content of whole blood, this time divided by the platelet count, as measured at baseline and on day 14. Adjusting the whole blood 5-HT content with the platelet count in this fashion is expected to help reduce inter-individual and intra-individual variance. Flament et al. (1987) found that the mean level of 5-HT changed from 49 to $45 \mathrm{ng} / 10^{8}$ platelets after five weeks of treatment with placebo, whereas it dropped to $2 \mathrm{ng} /$ $10^{8}$ platelets with clomipramine treatment.

\section{Assessment of NE Reuptake}

Tyramine acts indirectly as a sympathomimetic agent. It is taken up in NE neurons by the NE transporter and then releases NE from its intraneuronal stores (Ishigooka et al. 1997). In turn, NE acts on postsynaptic adrenoceptors to cause an elevation of systolic BP. Pretreatment with desipramine, which blocks the highaffinity NE reuptake site, prevents the increase in BP that usually follows tyramine administration (Hoffman and Lefkowitz 1990) by preventing tyramine from entering the NE neurons. The tyramine test consists of measuring the increase in systolic BP of patients following a fixed dose of tyramine, or the dose of tyramine necessary to cause a predetermined increase in systolic BP, such as $30 \mathrm{~mm} \mathrm{Hg}$ (Ghose et al. 1976). A decrease in the pressor response to the same doses of tyramine before a given treatment, or an increase in the dose of tyramine necessary to cause a given increase in systolic BP, may be considered an index of NE reuptake blockade.

Blockade by a drug of vascular postsynaptic $\alpha$-adrenoceptors might also be expected to decrease tyramine pressor response (Ghose 1984). Some commercially available antihypertensive agents, such as prazosin, are known to act by blocking the $\alpha_{1}$-adrenoceptors and thereby producing vasodilation. Recently, however, Schäfers et al. (1997) reported that the $\alpha_{1}$ adrenoceptor antagonist doxazosin did not decrease tyramine pressor response, although the $\beta_{1}$-adrenoceptor antagonist bisoprolol did. They proposed that the rise in systolic BP obtained with intravenous tyramine infused over 15 minutes reflects a $\beta_{1}$-adrenoceptor-mediated positive inotropic effect rather than a vascular pressor response. Regardless of whether the pressor response to tyramine is mediated through $\alpha$-adrenoceptors or $\beta$-adrenoceptors, if tyramine is prevented from entering NE nerve terminals, it should not be able to cause NE release and thus should not cause any change in blood pressure. In the present study, the pressor response to tyramine was considered to provide specifically an index of NE reuptake blockade by duloxetine, since duloxetine has no affinity for either $\alpha$-adrenoceptors or $\beta$-adrenoceptors. The possible contributions of $\alpha$ - and $\beta$-adrenoceptor activity to the effects of clomipramine and other agents are addressed further in the discussion later in this paper. 
The effects of two fixed doses of intravenous tyramine ( 4 and $6 \mathrm{mg}$ ) on systolic BP were assessed. The choice to measure blood pressure response to a fixed dose of tyramine (rather than to estimate the dose of tyramine necessary to produce a given change in blood pressure) was made with the expectation that duloxetine- and/or clomipramine-treated subjects would require large doses of tyramine to produce increases of $\geqslant 30 \mathrm{~mm} \mathrm{Hg}$ in systolic blood pressure, such that medical complications might result. Blockade of NE reuptake was expected to manifest itself by a decrease in the elevation of BP that was shown prior to drug administration (effect of tyramine measured on day 0 ).

In response to the physiological challenge of standing up, NE plasma levels usually increase (Ghose and Turner 1975). Following a 5-week treatment with clomipramine, Flament et al. (1987) found an increased elevation of plasma NE levels on standing up, presumably due to an increased synaptic availability of NE secondary to NE reuptake blockade. In our study, to evaluate NE reuptake inhibition further, supine and standing NE plasma levels were measured by HPLC.

The following procedure was followed at each visit: the subject was connected to a Criticare 408 apparatus, which automatically registers the heart rate (HR) and blood pressure, and a catheter installed in one arm. Following a resting period of 30 minutes in supine position, during which $\mathrm{HR}$ and $\mathrm{BP}$ were recorded every 10 minutes, blood was drawn for 5-HT, NE, and study drug level measurements. The participant then stood up for 5 minutes, at which point BP and HR were recorded, and blood was once again drawn for NE level measurement.

After another 30-minute period in supine position, a test dose of $0.5 \mathrm{mg}$ of tyramine was administered intravenously in order to rule out the presence of a pheochromocytoma which would not have been detected by the physical examination and laboratory tests. After 5 minutes, and if there was no significant elevation in blood pressure after the test dose, a dose of $4 \mathrm{mg}$ of tyramine was administered. The BP and HR were then measured every 2 minutes for 10 minutes. This time period allowed us to detect the peak increase in $\mathrm{BP}$, which usually occurs 2 minutes after the injection of tyramine, and provided sufficient time to let BP return to its baseline level. If the increase in $\mathrm{BP}$ did not reach $30 \mathrm{~mm}$ of $\mathrm{Hg}$ after the $4 \mathrm{mg}$ dose of tyramine, an additional dose of $6 \mathrm{mg}$ was given, and the BP and HR were measured as just described.

\section{Evaluation and Statistical Analysis}

The pressor response to tyramine was considered to be the difference between the systolic blood pressure measured 2 minutes after the tyramine infusion was complete, and that just prior to it. Serotonin reuptake data is expressed in concentrations in 5-HT in pmol/L and in 5-HT content of $10^{9}$ platelets compared to the baseline levels. Analysis of variance (ANOVA) for repeated measures (treatment $\times$ time) was performed on the data to assess the effects of the different drug regimens on the following parameters: 1) concentrations of 5-HT; 2) ratio of 5 -HT per $10^{9}$ platelets at baseline and day 14 ; 3) pressor response to a load of $4 \mathrm{mg}$ of tyramine; 4) pressor response to a load of $6 \mathrm{mg}$ of tyramine; 5) NE concentrations; 6) supine and standing pulse; 7) supine and standing systolic BP; and 8) supine and standing diastolic BP. Post-hoc analyses were conducted where appropriate with Tukey's test. Linear regression analyses were conducted between the drug plasma levels and the 5-HT concentrations and the pressor response to tyramine. All values are expressed as means \pm SEM unless indicated otherwise. The level of significance was $p<.05$.

\section{RESULTS}

\section{Subjects}

A total of 27 healthy male volunteers completed the study. The average age of the subjects was $24 \pm 1$ year (mean $\pm \mathrm{SEM}$ ). They weighted on average $72.7 \pm 2 \mathrm{~kg}$, and their average height was $174.2 \pm 1.2 \mathrm{~cm}$. Mean body mass index, calculated by dividing the weight (in $\mathrm{kg}$ ) by the square of the height (in meters), was 24 . There was no significant difference between subject groups for age, height, weight, or body mass index.

\section{Effects on 5-HT Reuptake}

The first 11 samples were lost during preparation. A total of 16 samples were available for analysis of 5-HT concentrations (Figure 1). The data for 5-HT collected for one of these subjects was withdrawn from all further analysis because the measured baseline 5-HT level was $195 \mathrm{pmol} / \mathrm{ml}$ of whole blood, a result which was clearly outside the range of two standard deviations (S.D. $=851 \mathrm{pmol} / \mathrm{ml}$ of blood) of the mean for the rest of the subjects at that point: $2086 \mathrm{pmol} / \mathrm{ml}$ of whole blood. An undetected technical error might be responsible for this aberrant result.

There was a significant interaction between treatment group and time of testing $\left[\mathrm{F}_{6,22}=6.82 ; p<.01\right]$. Simple main effect tests revealed that, while placebo had no significant effect on whole blood 5-HT concentrations $\left[\mathrm{F}_{2,22}=1 ; p>.05\right]$, clomipramine treatment, as well as both duloxetine regimens, significantly decreased 5-HT levels $\left[\mathrm{F}_{2,22}=34.22,30.67\right.$, and 23.97, respectively; $p<.0001]$. Indeed, 5-HT levels had significantly decreased from baseline as early as on day 7 for subjects receiving clomipramine and duloxetine $20 \mathrm{mg}$ / day, and those levels did not decrease any further the 


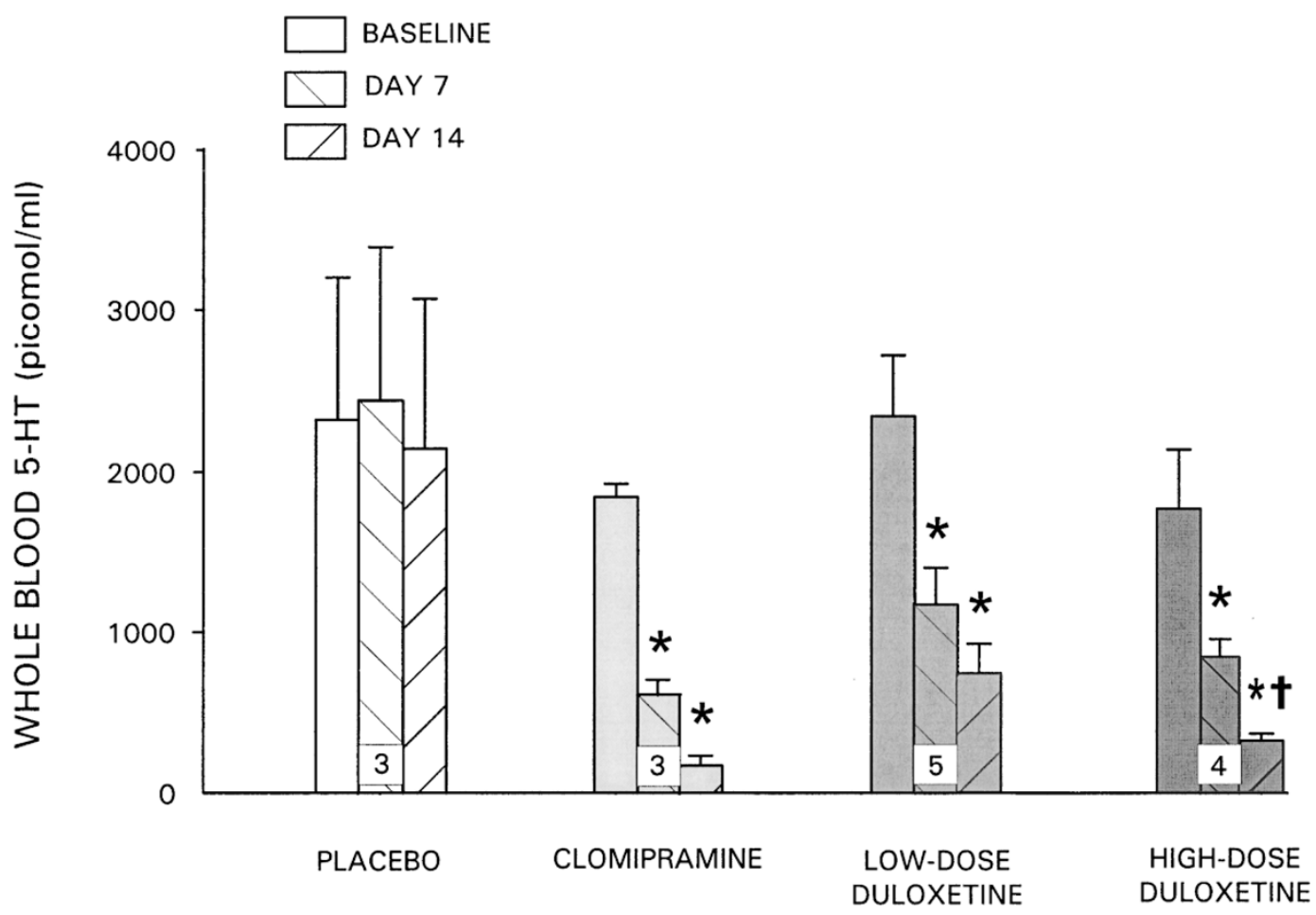

Figure 1. Mean $( \pm \mathrm{SEM})$ whole blood 5-HT concentration $(\mathrm{pmol} / \mathrm{ml})$ per treatment group. Measures were obtained at baseline, after 7 days and after 14 days of drug administration. $\left(^{*}\right)$ indicates a significant change from baseline and $(+)$ a significant change from day 7.

following week. Subjects on the duloxetine dose-escalation regimen $(40 \mathrm{mg} /$ day on day 7 and $60 \mathrm{mg} /$ day on day 14) also had a significant decrease in whole blood 5 -HT concentrations on day 7 , but with this dose there was a significant further decrease in 5-HT levels during the following week of treatment, suggesting a dosedependent response.

Similar analyses were conducted on the 5-HT content of $10^{9}$ platelets at baseline compared to that on day 14. Results show that the 5-HT content of $10^{9}$ platelets was significantly decreased from baseline in subjects taking clomipramine, duloxetine $20 \mathrm{mg} /$ day, and duloxetine $60 \mathrm{mg} /$ day $\left[\mathrm{F}_{1,10}=23.88,19.61\right.$, and 24.76, respectively; $p<.01$, whereas placebo had no effect on that parameter $\left[\mathrm{F}_{1,10}=0.01 ; p>.05\right]$.

\section{Effects on NE Reuptake}

NE Plasma Levels. There was no significant difference between groups in supine NE plasma levels $\left[\mathrm{F}_{3,23}=0.49, p=.69\right]$ at any time of testing, nor was there a significant interaction between treatment group and time of testing $\left[\mathrm{F}_{6,46}=1.66, p=.15\right]$. Similarly, there was no difference in standing NE levels $\left[\mathrm{F}_{3,23}=1.59\right.$, $p=.21]$, and there was no interaction between treatment groups and time of testing $\left[\mathrm{F}_{6,46}=0.72, p=.63\right]$. Since these results did not reveal significant differences, the raw data are not presented.
Vital Signs. There was no significant difference between treatment groups with regard to standing systolic $\mathrm{BP}\left[\mathrm{F}_{3,23}=0.30, p=.83\right]$ and standing diastolic BP $\left[\mathrm{F}_{3,23}=1.13, p=.36\right]$, nor was there an interaction between treatment groups and time of testing for those parameters $\left[\mathrm{F}_{6,46}=1.80, p=.12\right.$ and $\mathrm{F}_{6,44}=0.99, p=.44$, respectively]. The standing diastolic $B P$ value was unavailable for one subject at baseline, therefore the data for that parameter were removed from the analysis for standing diastolic BP.

There was, however, a significant interaction between time of testing and treatment group for the following parameters: supine pulse $\left[\mathrm{F}_{6,46}=4.36, p=.002\right]$, standing pulse $\left[\mathrm{F}_{6,46}=2.89, p=.02\right]$, supine systolic $\mathrm{BP}$ $\left[\mathrm{F}_{6,46}=2.22, p=.057\right]$, and supine diastolic $\mathrm{BP}\left[\mathrm{F}_{6,46}=\right.$ $2.90, p=.02]$. Simple main effect tests revealed that clomipramine significantly increased both supine and standing pulse, as well as the supine diastolic BP, on day 7 and day 14, when compared to baseline. However, there were no significant changes in those parameters from day 7 to day 14 in the subjects taking clomipramine. Clomipramine did not, at any time, significantly change the supine systolic BP, whereas volunteers receiving the high-dose duloxetine $(60 \mathrm{mg} /$ day) had a significant increase in supine systolic BP on day 14, when compared to baseline.

There was no significant difference in supine systolic $\mathrm{BP}$ in the high-dose duloxetine group between baseline 
and day 7 , when the dose was $40 \mathrm{mg}$ /day, nor was there a difference on that parameter between day 7 and 14. High-dose duloxetine was not associated with significant changes in measurements which clomipramine had effects on, namely the supine pulse, standing pulse, and supine diastolic BP. Placebo and the lower dose of duloxetine had no significant effects on cardiovascular parameters. Cardiovascular measures are summarized in Table 1.

Tyramine $4 m g$. The ANOVA for repeated measures showed that there was an interaction between the day of testing and the increase in systolic BP caused by the intravenous administration of $4 \mathrm{mg}$ of tyramine $\left[\mathrm{F}_{6,46}=\right.$ $2.44 ; p<.05]$ (Figure 2) . A simple main effect test indicated that there was a difference in the increase in systolic BP over time in subjects taking clomipramine $\left[\mathrm{F}_{2,46}=\right.$ 5.06; $p<.05$ ], but not in subjects receiving placebo and both duloxetine regimens $\left[\mathrm{F}_{2,46}=0.22,0.14\right.$, and 3.03, respectively; $p>$.05]. Post-hoc analysis of the results indicated that the mean increase in blood pressure in subjects taking clomipramine was significantly reduced on days 7 and 14, when compared to baseline. However, there was no significant difference in the pressor response presented on day 7 and day 14 for these same subjects.

Tyramine $6 \mathrm{mg}$. Two subjects were removed from the statistical analysis for this parameter because they had shown an increase in systolic BP near or superior to 30 $\mathrm{mm} \mathrm{Hg}$ after the administration of $4 \mathrm{mg}$ of tyramine at one point or another in the study, so they did not receive the $6 \mathrm{mg}$ dose of tyramine on that visit. Thus, since some data were missing for them, it was deemed appropriate to remove them altogether from the statistical analysis. Similar analyses were performed on the measured pressor response to $6 \mathrm{mg}$ of intravenous tyramine (Figure 3). As expected, results show that there was an interaction between the day of testing and the increase in systolic BP caused by the intravenous administration of tyramine $\left[\mathrm{F}_{6,46}=3.08 ; p<.05\right]$. Once again, a simple main-effect test indicated that there was a significant difference in systolic BP over time only in subjects taking clomipramine $\left[\mathrm{F}_{2,46}=8.85 ; p<.001\right]$, but not in subjects receiving placebo, duloxetine $20 \mathrm{mg}$ /day or duloxetine $60 \mathrm{mg} /$ day $\left[\mathrm{F}_{2,46}=0.34,0.89\right.$, and 0.64 , respectively; $p>$.05].

Post-hoc analysis of the results indicated that the mean increase in blood pressure in subjects taking clomipramine was significantly lower on days 7 and 14 than at baseline. However, there was no significant difference between their pressor response on day 7 and that on day $14(p>.05)$.

\section{Drug Plasma Levels}

The average clomipramine level was $34.9 \pm 5.5 \mathrm{ng} / \mathrm{ml}$ of plasma $(n=6)$ on day 7 and $93.1 \pm 24.2 \mathrm{ng} / \mathrm{ml}$ on day 14 , whereas those of desmethylclomipramine were $21.0 \pm 3.4$ and $73.2 \pm 11.6 \mathrm{ng} / \mathrm{ml}$, respectively. Linear regression analysis showed that there was no signifi-

Table 1. Effects of the Different Drug Regimens on The Cardiovascular Parameters

\begin{tabular}{|c|c|c|c|c|c|}
\hline Parameter & Group & & Baseline & Day 7 & Day 14 \\
\hline \multirow[t]{8}{*}{ Systolic blood pressure (mm Hg) } & \multirow[t]{2}{*}{ Placebo } & Supine & $113 \pm 4$ & $116 \pm 2$ & $113 \pm 5$ \\
\hline & & Standing & $123 \pm 5$ & $118 \pm 3$ & $122 \pm 6$ \\
\hline & \multirow[t]{2}{*}{ Clomipramine } & Supine & $115 \pm 4$ & $122 \pm 5$ & $121 \pm 5$ \\
\hline & & Standing & $122 \pm 4$ & $119 \pm 2$ & $127 \pm 5$ \\
\hline & \multirow[t]{2}{*}{ Low dose } & Supine & $115 \pm 5$ & $115 \pm 3$ & $112 \pm 3$ \\
\hline & & Standing & $122 \pm 5$ & $122 \pm 4$ & $114 \pm 3$ \\
\hline & \multirow[t]{2}{*}{ High dose } & Supine & $114 \pm 2$ & $115 \pm 1$ & $121 \pm 2^{*}$ \\
\hline & & Standing & $120 \pm 3$ & $120 \pm 4$ & $127 \pm 3$ \\
\hline \multirow[t]{8}{*}{ Diastolic blood pressure (mm Hg) } & \multirow[t]{2}{*}{ Placebo } & Supine & $59 \pm 3$ & $63 \pm 4$ & $58 \pm 4$ \\
\hline & & Standing & $66 \pm 3$ & $64 \pm 3$ & $67 \pm 3$ \\
\hline & \multirow[t]{2}{*}{ Clomipramine } & Supine & $61 \pm 3$ & $67 \pm 3^{*}$ & $68 \pm 2^{*}$ \\
\hline & & Standing & $72 \pm 3$ & $72 \pm 3$ & $72 \pm 2$ \\
\hline & \multirow[t]{2}{*}{ Low dose } & Supine & $62 \pm 3$ & $60 \pm 2$ & $57 \pm 2$ \\
\hline & & Standing & $72 \pm 5$ & $72 \pm 3$ & $62 \pm 4$ \\
\hline & \multirow[t]{2}{*}{ High dose } & Supine & $61 \pm 2$ & $61 \pm 2$ & $62 \pm 2$ \\
\hline & & Standing & $66 \pm 7$ & $71 \pm 3$ & $71 \pm 2$ \\
\hline \multirow[t]{8}{*}{ Pulse (beats/min) } & \multirow[t]{2}{*}{ Placebo } & Supine & $66 \pm 2$ & $71 \pm 2$ & $71 \pm 4$ \\
\hline & & Standing & $86 \pm 4$ & $88 \pm 7$ & $85 \pm 4$ \\
\hline & \multirow[t]{2}{*}{ Clomipramine } & Supine & $66 \pm 6$ & $78 \pm 7^{*}$ & $81 \pm 7^{*}$ \\
\hline & & Standing & $90 \pm 7$ & $110 \pm 7^{*}$ & $108 \pm 8^{*}$ \\
\hline & \multirow[t]{2}{*}{ Low dose } & Supine & $68 \pm 5$ & $60 \pm 3$ & $62 \pm 3$ \\
\hline & & Standing & $83 \pm 6$ & $75 \pm 3$ & $79 \pm 3$ \\
\hline & \multirow[t]{2}{*}{ High dose } & Supine & $62 \pm 3$ & $62 \pm 2$ & $60 \pm 2$ \\
\hline & & Standing & $78 \pm 4$ & $82 \pm 3$ & $82 \pm 5$ \\
\hline
\end{tabular}




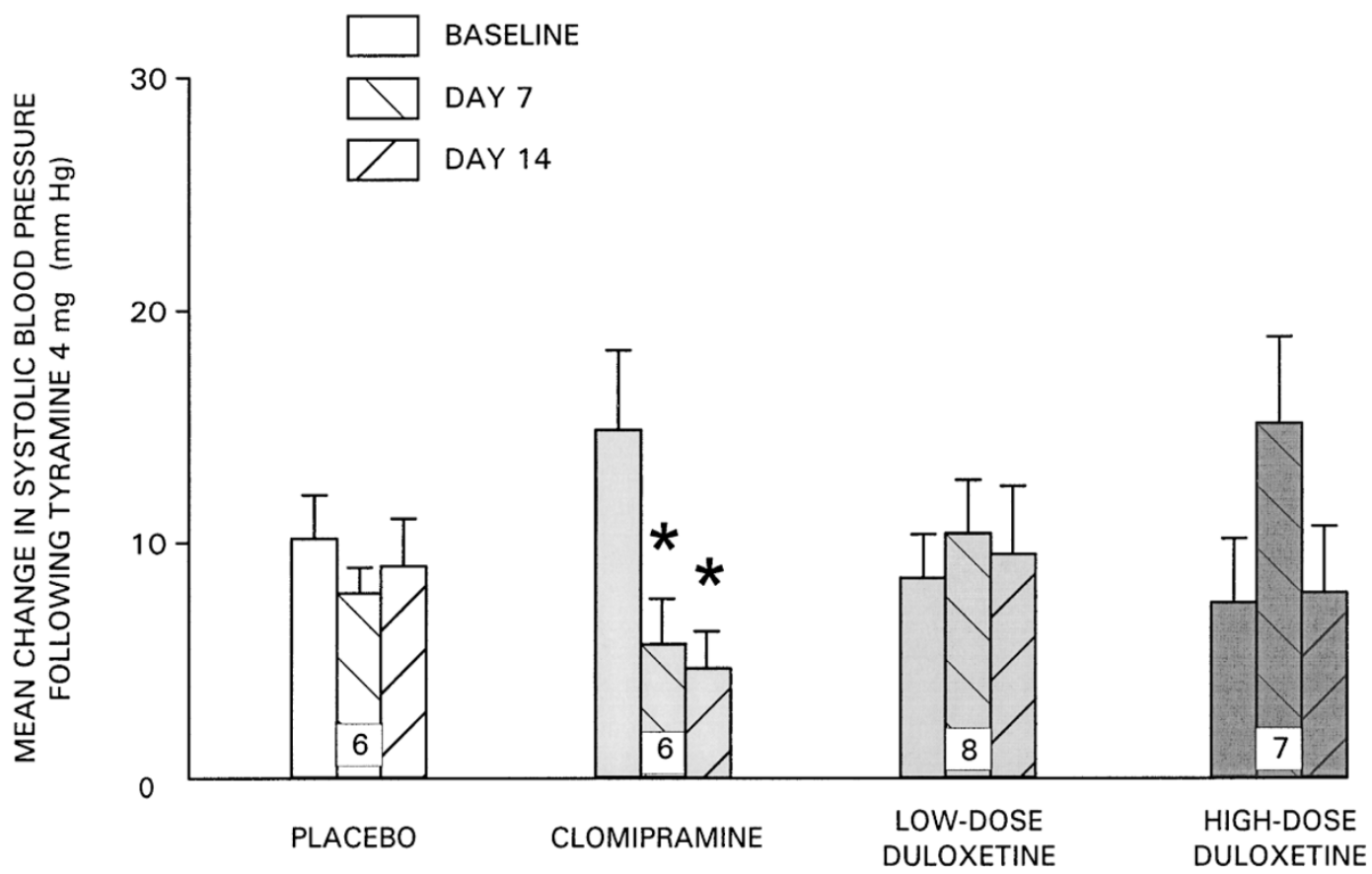

Figure 2. Mean ( \pm SEM) increase in systolic BP following the intravenous administration of $4 \mathrm{mg}$ of tyramine (in mm $\mathrm{Hg}$ ), per treatment group. Systolic BP measured at baseline, after seven days, and after 14 days of drug administration. $\left(^{*}\right)$ indicates a significant change from baseline.

cant linear relationship between either clomipramine or desmethylclomipramine plasma levels and the pressor response to tyramine at any time during the study. Furthermore, there was no significant linear relationship between clomipramine levels and 5-HT concentrations.

In the subjects taking $20 \mathrm{mg}$ of duloxetine per day, the average plasma level of the medication was $6.0 \pm$ $2.1 \mathrm{ng} / \mathrm{ml}$ on day 7 and $8.6 \pm 2.3 \mathrm{ng} / \mathrm{ml}$ on day 14 . There was no significant difference in duloxetine plasma levels between day 7 and day $14[\mathrm{~W}(8)=28$; $p>.05]$ in that group. In subjects taking the duloxetine dose-escalation regimen, the drug concentration on day 7 , when they reached the $40 \mathrm{mg} /$ day dose, was $15.1 \pm$ $1.9 \mathrm{ng} / \mathrm{ml}$ and that on day 14 was $27.9 \pm 6.6 \mathrm{ng} / \mathrm{ml}$. The difference in plasma concentration between day 7 and day 14 was not quite significant $[\mathrm{t}(6)=-2.30 ; p=.06]$ for that group of subjects either. There was no correlation between the duloxetine plasma level and the pressor response to tyramine, nor was there a linear relationship between the plasma level of the drug and the whole blood 5-HT level, at any of the different times of testing.

\section{DISCUSSION}

The aim of this study was to assess the effects of duloxetine on the 5-HT and the NE reuptake processes in healthy male subjects. Duloxetine, at doses of 20,40, and $60 \mathrm{mg} /$ day, significantly interfered with the 5-HT reuptake processes, as demonstrated by the decrease in blood 5-HT concentrations. However, the same doses of duloxetine failed to impede the usual increase in blood pressure that follows a tyramine intravenous infusion, indicating that this drug did not alter the NE reuptake process. The tricyclic antidepressant clomipramine, known to potently inhibit both the NE and the 5-HT reuptake process, caused a significant decrease in whole blood 5-HT concentration and also markedly reduced the pressor response to tyramine. The effectiveness of clomipramine to decrease both the 5-HT concentration and the pressor response to tyramine supports the validity of the assays used in this study and the conclusion that, at doses tested on our population of healthy volunteers, duloxetine acted as a selective 5-HT reuptake inhibitor, while having no effect on the NE reuptake process.

There was a high between-subject variability in duloxetine plasma levels. This was not unexpected given that other commercially-available SSRIs show similar between-subject variabilities in plasma levels, with, for example, a five-fold difference in the plasma levels of the SSRI paroxetine at the standard effective dose of 20 $\mathrm{mg} /$ day.

The finding of a significant 5-HT reuptake blockade by duloxetine is in keeping with results from animal studies (Wong et al. 1993; Engleman et al. 1995; Kasamo et al. 1996; Fuller et al. 1994; Kihara and Ikeda 1995) and previous studies performed on platelets of human volunteers (Wong et al. 1993; Ishigooka et al. 1997). The 


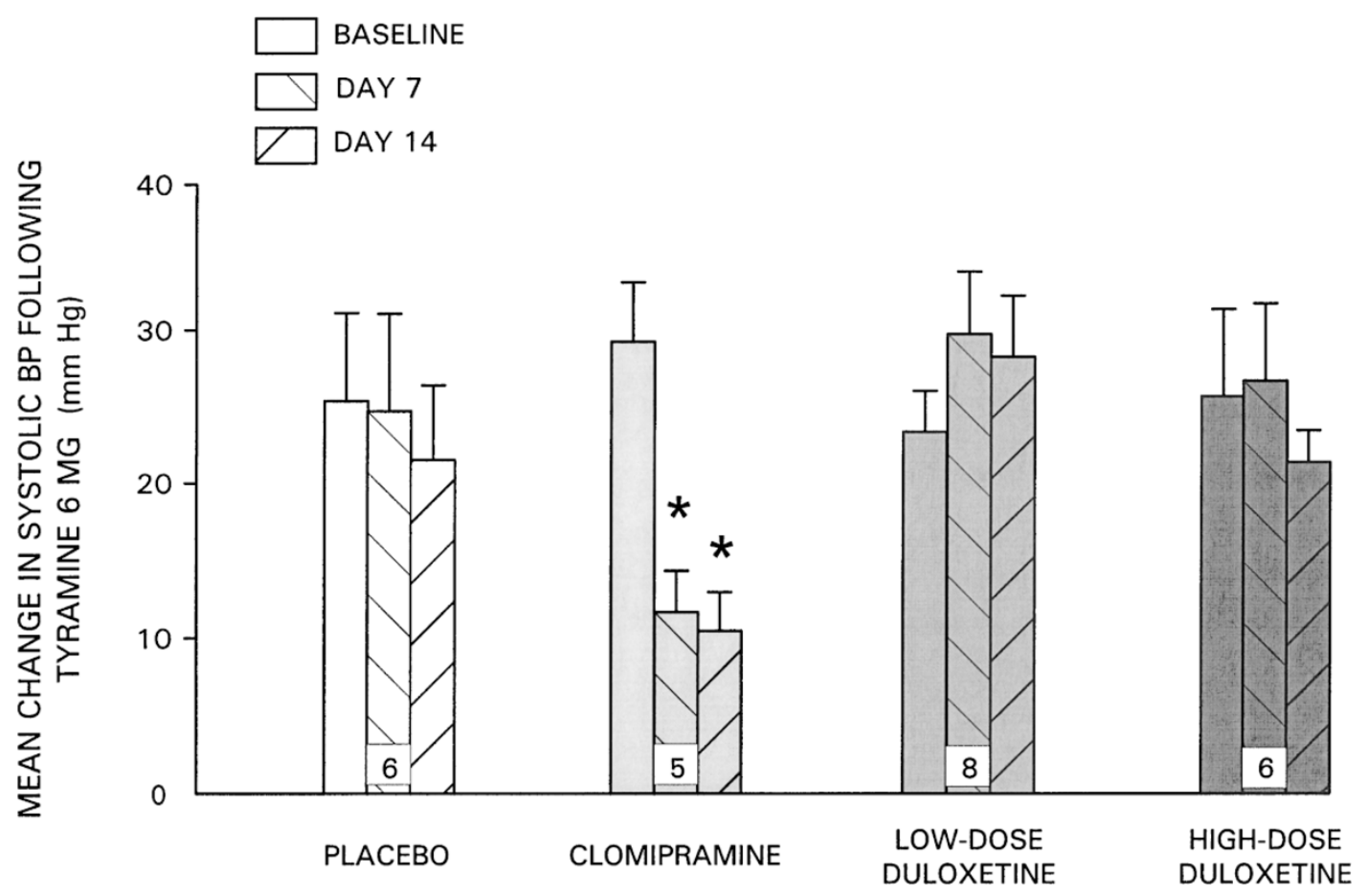

Figure 3. Mean ( \pm SEM) increase in systolic BP following the intravenous administration of $6 \mathrm{mg}$ of tyramine (in mm $\mathrm{Hg}$ ) per treatment group. Systolic BP measured at baseline, after seven days, and after 14 days of drug administration. $\left({ }^{*}\right)$ indicates a significant change from baseline.

fact that there was no correlation between duloxetine or clomipramine plasma levels and 5-HT concentrations can be explained by the marked potency of these drugs to block 5-HT reuptake even at the lowest dose used. For example, in a previous study conducted in our laboratory using the same experimental paradigm, paroxetine, a SSRI with a high affinity for the 5-HT carrier, but not the much weaker SSRI nefazodone, blocked the 5-HT reuptake process (Debonnel et al. 1998). The lack of effect of nefazodone on the 5-HT reuptake process in this case, in addition to its weaker potency to block 5-HT reuptake, could be explained by its short half-life. Indeed, the activity of the 5-HT carrier probably returned to normal between the two daily administrations of nefazodone, thus precluding a depletion of the platelet stores of 5-HT.

As expected, clomipramine significantly decreased the pressor response to intravenous administration of tyramine. This effect, however, was less pronounced than that obtained with desipramine, which practically abolished the pressor response to tyramine in the abovementioned study (Debonnel et al. 1998). The in vitro inhibition of NE uptake caused by desipramine is stronger than that caused by clomipramine, but not that of its metabolite, desmethylclomipramine. The halfmaximally effective drug concentration (the $\mathrm{IC}_{50}$ value) of desipramine is $1.2 \mathrm{nM}$ on $\left[{ }^{3} \mathrm{H}\right] \mathrm{NE}$ uptake in rat brain preparations, whereas that of desmethylclomipramine is $0.5 \mathrm{nM}$ and that of clomipramine is $60 \mathrm{nM}$ (Baldessarini 1985).

Given that the mean plasma concentration of desmethylclomipramine was $73.2 \pm 11.6 \mathrm{ng} / \mathrm{ml}$ (on day 14) and that of desipramine was lower in the previous study, it appears at first glance difficult to account for the lesser effect of the clomipramine treatment when compared to the abovementioned desipramine regimen (100 mg / day). Possibly, in comparison to desipramine, clomipramine's greater affinity for $\alpha_{1}$-adrenoceptors or its greater antagonism of muscarinic receptors, an action which Shäfers et al. (1997) suggest may enhance the pressor response to tyramine, may explain why clomipramine produced a lesser attenuation of the tyramine pressor response. Further studies in animals and humans using tricyclic and non-tricyclic NE reuptake inhibitors with different affinities for adrenergic and muscarinic receptors should help resolve this apparent discrepancy. These experiments are presently ongoing in our laboratory.

The lack of effect of duloxetine on the tyramine pressor response was an unexpected finding since animal studies have repeatedly shown that it blocks NE reuptake in vivo (Wong et al. 1993; Engleman et al. 1995; Kasamo et al. 1996; Fuller et al. 1994; Kihara and Ikeda 1995). This cannot be accounted for by an effect of duloxetine at $\alpha_{1}$ - or $\beta_{1}$-adrenoceptors or at muscarinic receptors since it has no affinity for these receptors 
(Wong et al. 1993). Furthermore, a possible desensitization of peripheral $\beta$-adrenoceptors (which might be expected to attenuate pressor response to tyramine) by duloxetine and the tricyclic antidepressants is unlikely to have contributed a significant role in the present study because these drugs produce this adaptive change in the brain only after long-term administration (see Wong 1998). Therefore, there is the possibility that insufficient doses of duloxetine were used to block NE reuptake. Animal studies have demonstrated duloxetine to be only about twice as potent in blocking the reuptake of 5-HT as it is in blocking that of NE (Wong et al. 1993; Kasamo et al. 1996). Since the reuptake of 5-HT was inhibited in our human volunteers at the lowest dosage (20 mg/day), it seems unlikely that the $60 \mathrm{mg} /$ day regimen was insufficient to block the NE carrier. Nonetheless, differences between animals and humans in relative potencies for blocking $\mathrm{NE}$ and 5-HT reuptake or in the absorption, distribution, and metabolism of duloxetine may be such that the $60 \mathrm{mg} /$ day regimen was less than necessary to achieve a detectable amount of NE reuptake blockade.

Another possibility to explain the lack of efficacy of duloxetine to suppress the pressor response to tyramine comes from the study of venlafaxine, another putative dual uptake inhibitor of 5-HT and NE. In a previous study (Debonnel et al. 1998), venlafaxine in doses up to $300 \mathrm{mg} /$ day had no effect on the pressor response to tyramine in healthy volunteers. One tentative explanation is that venlafaxine and duloxetine might interact with a different NE reuptake site, yet to be identified, than tricyclic antidepressants, thereby producing differential effects on the indirectly-acting sympathomimetic tyramine. Indeed, in the case of venlafaxine, it has been shown that there is a marked discrepancy between its affinity with the NE carrier, using $\left[{ }^{3} \mathrm{H}\right]$-nisoxetine as a ligand, which is extremely low, and its great potency to block NE reuptake in vivo. This finding would support the idea of two distinct uptake sites for NE. This is, however, not the case with duloxetine, as duloxetine is endowed with both a high affinity for the NE carrier, using $\left[{ }^{3} \mathrm{H}\right]$-nisoxetine as a ligand, and a high potency to block NE reuptake in vivo (Béique et al. 1998, 1999).

An additional intriguing result comes from the study of depressed patients who underwent the same procedure as in the present study before and during a venlafaxine treatment (Debonnel et al. 1998). In the latter study, the pressor response to tyramine of patients receiving $225 \mathrm{mg} /$ day of venlafaxine was significantly decreased after a 7-day titration, which stands in sharp contrast to the lack of effect of venlafaxine in our healthy volunteers, even if the dose used in the volunteers was higher $(300 \mathrm{mg} /$ day). Thus, it is possible that the NE reuptake process is differentially modulated in healthy volunteers and depressed patients. This hypothesis is supported by results from other investigators showing an increased sensitivity to tyramine in depressed patients, compared to control subjects (Coppen and Ghose 1978; Friedman 1978; Klimek et al. 1997). The biological basis for this difference remains to be elucidated, but a few possibilities can be envisaged. De-

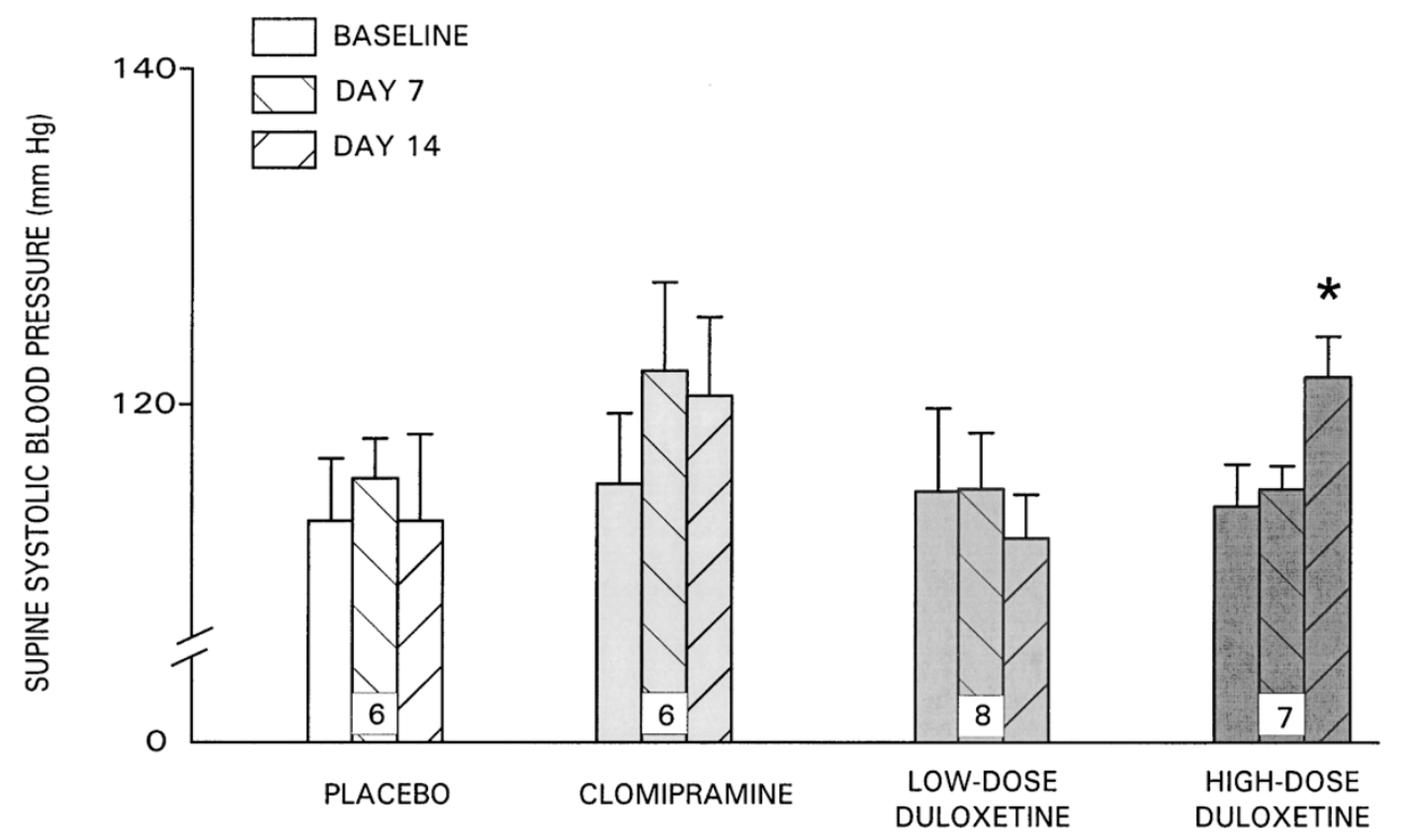

Figure 4. Systolic BP in $\mathrm{mm} \mathrm{Hg}$ (mean $\pm \mathrm{SEM}$ ) in supine position (prior to injection of tyramine) per treatment group. $\left(^{*}\right)$ indicates a significant change from baseline. 
pressed patients might have fewer NE carrier sites; the physiological reuptake process of NE would then be easier to block. Indeed, a study comparing $\left[{ }^{3} \mathrm{H}\right]$-nisoxetine binding to NE carrier sites in brain tissue from depressed subjects to those of age-matched controls found that there was a decreased binding of the ligand in the midcaudal portion of the locus coeruleus in the depressed patients, indicating a decreased density of NE carriers (Klimek et al. 1997). Alternatively, the postsynaptic adrenoceptors mediating the effect of the released NE by tyramine may be more sensitive in depressed patients than in healthy volunteers. Finally, another explanation for the putative increased sensitivity of depressed patients to tyramine test is that the intraneuronal stores of NE may be greater in depressed patients than in volunteers.

Another interesting result is that there was no change in plasma NE levels, either supine or standing, in the volunteers. Those results stand in contrast to those of Flament et al. (1987) who found a significant increase in standing plasma NE levels in children with obsessive-compulsive disorders, following a five-week treatment with clomipramine. One possible explanation for this difference between their subjects and those of our present study is that the plasma levels of desmethyclomipramine, the metabolite of clomipramine with a high affinity for the NE reuptake site, attained in our study $(73 \pm 12 \mathrm{ng} / \mathrm{ml})$ were lower than those achieved in the study by Flament et al. $(208 \pm 86 \mathrm{ng} / \mathrm{ml})$. Nevertheless, some of our findings are in agreement with certain results reported by Flament et al. (1987): the increase in supine and standing pulse, as well as the increase in diastolic BP, in patients receiving clomipramine. The changes in these cardiovascular parameters may well represent a physiologic reaction to an increased availability of NE. None of these parameters were affected by the lower duloxetine regimen, which is in agreement with the lack of effect of this drug regimen on the pressor response to tyramine, suggesting no NE reuptake blockade. The higher dose of duloxetine (60 mg/day) did not alter any of the cardiovascular parameters except one: a significant increase in supine systolic BP on day 14 ( Figure 4). Importantly, this increase was not observed on day 7 , when the same subjects were receiving a lower dosage of duloxetine was used (40 mg/day). The possibility therefore remains that a dose of duloxetine of $60 \mathrm{mg} /$ day may represent the threshold for NE reuptake blockade, since doses of $20 \mathrm{mg} /$ day and $40 \mathrm{mg}$ /day did not increase the supine systolic BP, while a regimen of $60 \mathrm{mg} /$ day of duloxetine did. The fact that this parameter was not affected by the clomipramine regimen does not invalidate this interpretation. Indeed, the differential effects of duloxetine and clomipramine on supine systolic BP might be due to the blockade of $\alpha$-adrenoceptors by the latter drug only (Baldessarini 1985).
In conclusion, the present study has demonstrated that duloxetine acts as a selective 5-HT reuptake inhibitor in non-depressed human male volunteers, and that, at doses up to $60 \mathrm{mg} /$ day, it failed to inhibit the tyramine pressor response, as would be otherwise expected of a NE reuptake blocker. It would be interesting to determine whether daily dosages higher than $60 \mathrm{mg}$ / day could suppress the tyramine pressor response in healthy volunteers, and whether there would be any difference observed in this pressor response in depressed subjects versus healthy subjects.

\section{ACKNOWLEDGMENTS}

This work was supported in part by the Medical Research Council of Canada (MRC) grant MT-11014 and a Scientist Award to P.B., the Fonds de la Recherche en Sante du Quebec, Eli Lilly \& Co., and a fellowship to J.E.T. from the Royal Victoria Hospital Research Institute. We would like to thank Normand Lavoie for the assays of blood 5-HT levels.

\section{REFERENCES}

Artigas F, Sarrias MJ, Martinez E, Gelpi E (1985): Serotonin in body fluids: Characterization of human plasmatic and cerebrospinal fluid pools by means of a new HPLC method. Life Sci 37:441-447

Baldessarini RJ (1985): Chemotherapy in Psychiatry, Chapter 4. Antidepressants Agents, Harvard University Press, pp 154

Béïque JC, de Montigny C, Blier P, Debonnel G (1998): Blockade of 5-hydroxytryptamine and norepinephrine uptake by venlafaxine: Comparative study with paroxetine and desipramine. Brit J Pharmacol 125:526-532

Béïque JC, de Montigny C, Blier P, Debonnel G (1999): Venlafaxine: Discrepancy between in vivo serotonin and norepinephrine reuptake blockade and affinity for reuptake sites. Synapse 32:198-211

Berk M, du Plessis AD, Birkett M, Richardt D (1997): An open-label study of duloxetine hydrochloride, a mixed serotonin and noradrenaline reuptake inhibitor, in patients with DSM-III-R major depressive disorder. Int Clin Psychopharmacol 12:137-140

Blier P, de Montigny C (1999): Serotonin and drug-induced therapeutic responses in major depression, obsessivecompulsive and panic disorders. Neuropsychopharmacology 21(2S):91S-98S

Coppen A, Ghose K (1978): Peripheral alpha-adrenoreceptor and central dopamine receptor activity in depressive patients. Psychopharmacologia 59:171-177

Debonnel G, Blier P, Saint-André E, Hébert C, de Montigny C (1998): Comparison of the effects of low and of high doses of venlafaxine on serotonin and norepinephrine reuptake processes in patients with major depression and healthy volunteers. Int J Neuropsychopharmacol 1(Suppl.1):S17

Delgado PL, Miller HL, Salomon RM, Licinio J, Krystal JH, Moreno FA, lieninger GR, Charney DS (1999): Tryptophan-depletion challenge in depressed patients 
treated with desipramine or fluoxetine: Implications for the role of serotonin in the mechanism of antidepressant action. Biol Psychiatry 46:212-220

Demet EM, Halaris AE, Bhatarakamol S (1978): Indoleamine compartmentalization in human blood. Clin Chim Acta 89:285-292

Derivan A, Entsuah AR, Kikta D (1995): Venlafaxine: Measuring the onset of antidepressant action. Psychopharmacol Bull 31:439-447

Engleman ES, Perry KW, Mayle DA, Wong DT (1995): Simultaneous increases of extracellular monoamines in microdyalisates from hypothalamus of conscious rats by duloxetine, a dual serotonin and norepinephrine uptake inhibitor. Neuropsychopharmacology 12:287295

Flament MF, Rapoport JL, Murphy DL, Berg CJ, Lake CR (1987): Biochemical changes during clomipramine treatment of childhood obsessive-compulsive disorder. Arch Gen Psychiatry 44:219-225

Friedman M (1978): Does receptor supersensitivity accompany depressive illness? Am J Psychiatry 135:107-109

Fuller RW, Hemrick-Luecke SK, Snoddy HD (1994): Effects of duloxetine, an antidepressant drug candidate, on concentrations of monoamines and their metabolites in rats and mice. J Pharmacol Exp Ther 269:132-136

Ghose K (1984): Tyramine Pressor Test: Implications and limitations. Methods Find Exp Clin Pharmacol 6:455464

Ghose K, Gifford I, Turner P, Leighton M (1976): Studies of the interactions of desmethylimipramine with tyramine in man after a single oral dose and its correlation with the plasma concentrations. Br J Clin Pharmacol 3:335337

Ghose K, Turner P (1975): Intravenous tyramine pressor response in depression. Lancet 7920:1317-1318

Hoffman BB, Lefkowitz RJ (1990): Catecholamines and sympathomimetic drugs. In Goodman Gilman A, Rall TW, Nies AS, Taylor P (eds), The Pharmacological Basis of Therapeutics. New York, Pergamon Press, pp 187-220

Ishigooka J, Nagata E, Takahashi A, Sugiyama T, Uciumi M, Tsukahara T, Murasaki M, Miura S, Ogums T, Yano Y (1997): Simultaneous monitoring of inhibition of serotonin uptake by platelets and plasma drug concentrations following administration of duloxetine, a new antidepressant candidate, to healthy volunteers. Current Ther Res 10:679-692

Joubert AF, du Plessis AD, Faries D, Gagiano CA (1997): High placebo response rate versus clinical impression with the new antidepressant duloxetine. Biol Psychiatry 42(Suppl 1):229S

Kasamo K, Blier P, de Montigny C (1996): Blockade of the serotonin and norepinephrine uptake processes by duloxetine: In vitro and in vivo studies in the rat brain. J Pharmacol Exp Ther 277:278-286

Kihara T, Ikeda M (1995): Effects of duloxetine, a new serotonin and norepinephrine uptake inhibitor, on extracel- lular monoamine levels in rat frontal cortex. J Pharmacol Exp Ther 272:177-183

Klimek V, Stockmeier C, Overholser J, Meltzer HY, Kalka S, Dilley G, Ordway GA (1997): Reduced levels of norepinephrine transporters in the locus coeruleus in major depression. J Neurosci 17:8451-8458

Sigg EB (1986): Antidepressant biochemical profile of the novel bicyclic compound WY-45,030, an ethyl cyclohexanol derivative. Biochem Pharmacol 35:4493-4497

Nelson JC, Mazure CM, Bowers MB, Jatlow PI (1991): A preliminary open study of the combination of fluoxetine and desipramine for rapid treatment of depression. Arch Gen Psychiatry 48:303-307

Nelson JC (1998): Synergistic effects of serotoninergic and noradrenergic antidepressants. Int J Neuropsychopharmacol 1(Suppl 1):S17

Nierenberg AN, Feighner JP, Rudolph R, Cole JO, Sullivan J (1994): Venlafaxine for treatment-resistant unipolar depression. J Clin Psychopharmacol 14:419-423

Pletscher A (1968): Metabolism, transfer and storage of 5-hydroxytryptamine in blood platelets. Br J Psychiatry 32:1-16

Poirier MF, Boyer P (1999): Venlafaxine and paroxetine in treatment-resistant depression. Double-blind, randomized comparison. Br J Psychiatry 175:12-16

Schäfers RF, Poller U, Ponicke K, Geissler M, Daul AE, Michel MC, Brodde OE (1997): Influence of adrenoceptor and muscarinic blockade on the cardiovascular effects of exogenous noradrenaline and of endogenous noradrenaline released by infused tyramine. NaunynSchmiedeberg's Arch Pharmacol 335:239-249

Seth R, Jennings AL, Bindman J, Phillips J, Bergmann K (1992): Combination treatment with noradrenaline and serotonin reuptake inhibitors in resistant depression. $\mathrm{Br}$ J Psychiatry 161:562-565

Sharma A, Goldberg MJ, Cerimele BJ (2000): Pharmacokinetics and safety of duloxetine, a dual-serotonin and norepinephrine reuptake inhibitor. J Clin Pharmacol 40:161167

Wong DT (1998): Duloxetine (LY 248686): An inhibitor of serotonin and noradrenaline uptake and an antidepressant drug candidate. Exp Opin Invest Drugs 7(10):1-9

Wong DT, Bymaster FP, Mayle DA, Leroy RR, Krushinski JH, Robertson DW (1993): LY248686, a new inhibitor of serotonin and norepinephrine uptake. Neuropsychopharmacology 8:23-33

Yardley JP, Husbands GE, Stack G, Butch J, Bicksler J, Moyer JA, Muth EA, Andree T, Fletcher H, James MN (1990): 2Phenyl-2-(1-hydroxycycloalkyl)ethylamine derivatives: Synthesis and antidepressant activity. J Med Chem 33:2899-2905

Zucker MB (1965): Serotonin (5-hydroxytryptamine): Haematologic aspects. In Toscantinis LM (ed), Progress in Haematology. New York, Grune and Stratton 